\title{
Evaluation of gene flow in structured and seed blend refuge systems of non-Bt and Bt corn
}

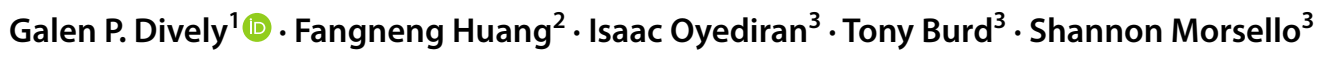

Received: 24 November 2018 / Revised: 12 May 2019 / Accepted: 24 May 2019 / Published online: 3 June 2019

(c) The Author(s) 2019

\begin{abstract}
Gene flow between Bt and non-Bt plants can have implications for resistance management. In 2013 and 2014, field trials in Maryland and Louisiana measured gene flow in three refuge systems: (1) structured refuge stand of purple-seeded corn flanked on both sides by stands of yellow corn; (2) seed blend of yellow corn containing purple corn as refuges; and (3) seed blend of purple-seeded corn containing yellow corn as refuges. The presence of cross-pollinated purple kernels was used as a marker to quantify gene flow. In the structured refuge, cross-pollination between $\mathrm{Bt}$ and structured refuge plants averaged $5.4 \%$ on adjacent rows and decreased significantly moving away from the interface. For refuge system 2, outcrossing of pollen from the refuge plants was $<1 \%$ in ears of neighboring Bt plants both within and on adjacent rows. Cross-pollination was generally higher for plants nearest to the refuge plant. In refuge system 3, outcrossing of pollen from neighboring Bt plants caused $18.6 \%$ refuge kernels expressing the purple trait. Laboratory bioassay showed that consumption of a meridic diet containing 6\% refuge kernel tissue collected from a 95:5\% seed blend field caused significant larval growth inhibition of the corn earworm, Helicoverpa zea (Boddie). Overall findings suggest that effects of gene outcrossing from refuge plants to $\mathrm{Bt}$ plants in the seed blend systems are likely not a great issue, but significant gene flow from neighboring Bt plants to refuge plants could reduce the number of homozygous susceptible larvae produced and favor survival of heterozygotes.
\end{abstract}

Keywords Bt corn $\cdot$ Gene flow $\cdot$ Seed blend refuge $\cdot$ Insect resistance management

\section{Key message}

- Cross-pollination between Bt and structured refuge plants averaged $5.4 \%$ on adjacent rows and decreased significantly moving away from the interface.

- Outcrossing of pollen from the refuge plant in a seed blend averaged $<1 \%$ in neighboring Bt ears, but was much greater from Bt pollen in the opposite direction, averaging $18.6 \%$ in refuge ears.

Communicated by Y. Gao.

Galen P. Dively

galen@umd.edu

1 Department of Entomology, University of Maryland, College Park, MD 20742, USA

2 Department of Entomology, Louisiana State University Agricultural Center, Baton Rouge, LA 70803, USA

3 Syngenta Crop Protection, LLC, Research Triangle Park, NC 27709, USA
- Diet bioassays incorporating kernel tissue from refuge plants in a 95:5\% seed blend caused significant growth inhibition of $H$. zea and $O$. nubilalis larvae.

\section{Introduction}

To prolong the durability of Bt crop technology, insect resistance management (IRM) plans are implemented to delay the evolution of resistance. The primary IRM tactic for transgenic corn expressing Bt insecticidal toxins is the high dose/ refuge strategy, where a refuge consisting of non-Bt corn is planted adjacent to (structured), or within (seed blend) the Bt corn (Gould 1998; Tabashnik et al. 2008; Huang et al. 2011; Onstad et al. 2011). The refuge provides an area for susceptible insect individuals to develop without selection for resistance to Bt toxins, and thus available to interbreed with potentially homozygous resistant individuals that may emerge from the Bt plants.

The seed blend or so-called 'refuge in a bag' system provides farmers with a convenient and easier compliance 
solution to satisfy federal regulations (Matten et al. 2012). Seed blend simplifies refuge management and allows farmers to plant Bt corn in every field, while still complying with refuge requirements. The blend of non-Bt plants interspersed with Bt plants serves as the refuge, which has become an essential component of current IRM plans for Bt corn in the US Corn Belt (Matten et al. 2012).

However, there is concern about the gene flow between $\mathrm{Bt}$ and non-Bt plants in seed blend plantings. Gene flow in plants occurs when pollen from one plant fertilizes another plant carrying with it the genes from the first plant. Pollenmediated gene flow between $\mathrm{Bt}$ and refuge plants could diminish the effectiveness of the seed blend refuge strategy for IRM. Gene flow to refuges from Bt plants can result in toxin expression in the kernels of refuge plants (Yang et al. 2014). Conversely, gene flow to Bt plants from refuges can reduce the toxin expression level in kernels of Bt plants. Both routes of gene contamination may affect target pests that feed on corn ears, such as the corn earworm, Helicoverpa zea (Boddie), and European corn borer, Ostrinia nubilalis (Hübner) (Horner et al. 2003; Burkness et al. 2011; Burkness and Hutchison 2012; Yang et al. 2014). Chilcutt and Tabashnik (2004) reported that cross-pollinated corn ears in the refuge can accelerate resistance evolution if fewer susceptible moths are produced in a refuge or if intermediate levels of toxin in cross-pollinated refuge ears kill susceptible individuals but allow heterozygotes to survive (Yang et al. 2017). Heuberger et al. (2008) studied the effect of refuge contamination in cotton growing systems on resistance evolution in the pink bollworm, Pectinophora gossypiella (Saunders). They concluded that Bt pollen contamination in the cotton ecosystem has negligible effects on resistance evolution in P. gossypiella, as long as contamination does not confer a selective advantage to heterozygotes over homozygous susceptible larvae. For these reasons, the seed blend refuge system was not considered an appropriate IRM strategy for single-gene Bt corn, and thus, all registered blended seed products contain pyramided Bt genes (USEPA 2011; Matten et al. 2012).

Corn is primarily wind-pollinated, with approximately 97\% outcrossing between plants and fertilization occurring at up to $200 \mathrm{~m}$ (Chilcutt and Tabashnik 2014). Research on corn pollen movement has focused on the use of modeling, small plot trials, or both to determine the likelihood of corn pollen moving from $\mathrm{Bt}$ to non-Bt hybrids, and distances that corn pollen may travel from the source field (Aylor 2002; Aylor et al. 2003; Chilcutt and Tabashnik 2004; Kuparinen et al. 2007; Bannert et al. 2008). Understanding the rate of gene flow between non-Bt and Bt plants during pollen shed is important in IRM, especially for seed blend systems. Here, we present results from field plot experiments to quantify the extent of cross-pollination in structured and seed blend refuge systems, using purple-seeded corn as a phenotypic marker. We also provide supportive information from laboratory bioassays as evidence of $\mathrm{Bt}$ toxin expression in ears of refuge plants in the seed blend system.

\section{Materials and methods}

\section{Field sites and treatments}

Field plot experiments were repeated over 2 years at the Central Maryland Research and Education Center, Beltsville, MD (2013 and 2014), and at two Louisiana State University Agricultural Center research stations in St. Joseph (2013) and Winnsboro, LA (2014). At all sites, two simulated refuge systems were established each year. System 1 represented a structured refuge consisting of a planting of purple-seeded (PS) plants (hybrid 'SL7571PG'; RM 113 days) flanked on both sides by stands of Bt yellowseeded (YS) plants (Agrisure hybrid 'NK1284-3000GT'; RM 112 days). System 2 represented a seed blend of Bt YS plants containing PS plants as refuges. Another seed blend planting (System 3) was evaluated only at the Maryland site in 2014 and consisted of PS plants containing its closely related non-Bt isoline YS plants (hybrid 'NK1284-GT'; RM 112 days) as refuges.

\section{Experimental plot design}

Plots of each refuge system, consisting of $7.5 \mathrm{~m}$ long rows spaced $20 \mathrm{~cm}$ apart, were arranged side by side within in each of four (MD) or five (LA) randomized complete blocks. A buffer strip of 12 rows of male-sterile non-Bt corn running the opposite way was planted between blocks. For the structured refuge system 1, each plot consisted of four rows of PS plants flanked on both sides by four rows of Bt YS plants. For the blended seed systems, each plot consisted of 12 rows of either Bt YS (System 2) or PS plants (System 3) with either PS (System 2) or non-Bt YS (System 3) refuge plants, respectively. Refuge plants were hand planted after machine seeding in rows $3,5,7$, and 9 and spaced $1.8 \mathrm{~m}$ apart, so that the eight refuge plants were not directly across from each other in the nearest adjacent rows. To ensure successful germination and seedling emergence, two seeds were planted at each refuge spot and marked with small stakes to identify refuge plants. At the two-leaf stage, the less vigorous seedling in a refuge spot was removed. Plots were seeded in early May at the LA sites and in late May at the MD site, using a no till corn planter to establish a stand of 64,200 plants per hectare. Each experiment consisted of either 8 (MD) or 10 (LA) plots, except for the Maryland experiment in 2014 which had 12 plots (three refuge systems replicated four times). For each experiment, standard fertility inputs were practiced according to site-specific nutrient 
management recommendations, and weeds were managed using pre- and post-emergent herbicide applications.

\section{Measurements of gene flow}

At the dough stage (R4), ear samples were collected from each refuge system to record the number of kernels expressing the purple color as a measure of cross-pollination. Any kernel showing partial or complete phenotypic expression of the purple trait was counted. In the structured refuge plots, ten randomly selected ears (LA) or all ears (MD) from the $\mathrm{Bt}$ YS plants on each row flanking the center four rows of PS plants were husked in situ and examined for purple kernels. Data were recorded on individual ears per row on each side of the center purple-seeded plants. For seed blend system 2, outcrossing of genes due to pollen drift from the PS refuge plants was estimated by the presence of purple kernels in ears of Bt YS neighboring plants around each refuge plant. Data on the number of purple kernels per ear were recorded on plants at 1,2,3,4, and 5 positions away from the refuge plant on both sides within the same row. Ears were also examined for purple kernels on five or six consecutive plants (depending on the study site) on the adjacent row on each side of the refuge plants. For seed blend system 3 consisting of PS plants with YS refuge plants (MD, 2014), ears of all refuge plants in each plot were examined to record the number of purple kernels, indicative of the potential crosspollination due to pollen drift from neighboring $\mathrm{Bt}$ plants. For each experiment, random samples of 10 ears in each plot were collected to record the number of kernel rows on each ear, length of kernel row $(\mathrm{cm})$, and number of kernels per $10 \mathrm{~cm}$.

\section{Tissue-incorporated feeding bioassay}

Laboratory bioassays of kernel tissue were conducted in 2015 to provide evidence of Bt toxin expression in ears of refuge plants in the seed blend system. Field plots of a pyramided Bt hybrid (SPS1031), expressing Cry1Ab and Vip3Aa20 toxins for lepidopteran control, and its closely related non-Bt hybrid (SPS1030) were established at the Central Maryland Research and Education Center, Beltsville, MD. Plots of 100\% Bt hybrid, 95:5 seed blend of the Bt hybrid and non-Bt refuge, and 100\% non-Bt hybrid were planted side by side in each of four randomized blocks. Each plot measuring 4 rows $4.6 \mathrm{~m}$ long was planted by hand on July 17 with 20 seeds per row spaced $23 \mathrm{~cm}$ apart. Each row of the seed blend treatment contained one refuge plant marked with a stake and placed at least $0.5 \mathrm{~m}$ away from the row ends.

Two ears at the dent stage (R5) were randomly collected from the center rows in each of the $100 \% \mathrm{Bt}$ and non-Bt plots, and from two refuge plants in each seed blend plot.
Kernels of each type were removed from the ears and pooled by replicate block as a composite sample, and then, a random subsample was frozen and dried in a freeze dryer. The lyophilized kernel tissue was ground to a fine powder in a commercial grinder (IKA Works, Inc, Wilmington, DE) and kept at $-80{ }^{\circ} \mathrm{C}$ until used in bioassays.

A diet-incorporated feeding bioassay consisting of a single concentration of each kernel tissue was conducted to measure the body weight gain of second instar $H$. zea and $O$. nubilalis. Eggs of laboratory colonies of both species obtained from Benzon Research (http://www.benzonrese arch.com/) were incubated in a growth chamber until hatch and then reared on a meridic diet (Southland Products, Lake Village, AR) until the 2nd instar for testing. Separate bioassays were conducted exposing individual larvae of each species to four replicates of each kernel type. For each replicate sample of kernel powder, $500 \mathrm{ml}$ of modified meridic diet (without soybean flour and adjusted with more water to offset the added kernel powder) was prepared, cooled to $55^{\circ} \mathrm{C}$ in a water bath, and then incorporated with $30.5 \mathrm{~g}$ of kernel powder. The dilution by adding kernel tissue resulted in a concentration of $60 \mathrm{mg}$ of kernel tissue per $\mathrm{ml}$ of diet. For each treatment, $\sim 1.5 \mathrm{~mL}$ of diet was dispensed into each of 64 wells of a 128-well bioassay tray (C-D International). After the diet cooled, one larva was placed in each well using a camel-hair brush. Wells were sealed with a perforated adhesive lid, and trays were held in a growth chamber at $25^{\circ} \mathrm{C}$. After 7 days, the weight of individual larvae was recorded, and the average weight gain per larva was calculated for each treatment by replicate group (16 larvae/ replicate).

\section{Statistical analyses}

The mean number of kernels per ear was calculated as [number of kernel rows per ear $\mathrm{x}$ number of kernels per row], using metrics recorded from ear samples in each plot. The percentage of purple kernels was then calculated as [number of purple kernels/mean number of kernels per ear $\times 100$ ] and analyzed as a surrogate estimate of the percentage of cross-pollination. Although the refuge systems were planted together in the same experimental plot layout, each system was analyzed separately using the Proc Mixed model of SAS Version 9.4 (SAS Institute 2013), with the focus on testing for differences among the nested factors. Furthermore, analyses were conducted by year and study site due to differences in sampling protocols and environmental conditions. For the structured refuge system 1, we tested for mean differences across individual rows and between means pooled over rows on each side of PS plants. The ANOVA model treated row as a fixed nested factor and corrected for repeated measures across rows that were spatially dependent. For seed blend system 2, we tested for differences among 
three plant position groups relative to the refuge plant, as a fixed nested factor. These groups included the pooled data from four ears surrounding the refuge plant at 1 and 2 plant positions away, six ears at 3,4 , and 5 plant positions away, and four ears for the nearest plants on adjacent rows. Data recorded on individual ears within a plot row or plant position were considered sub-sampling and thus averaged by replicate block before analysis. Data from seed blend system 3 were summarized as mean ( \pm standard error) percentage of kernels showing expression of the purple color in the refuge ears. In all analyses, replicate block was treated as a random effect, percentage data were arcsine transformed before the analysis, and Tukey's option was used to test for significance $(P<0.05)$ among multiple mean comparisons. For the bioassay data, differences in larval weight gain among the kernel tissue types were tested using a one-way ANOVA, after data transformations were made for lack of normality and unequal variances.

\section{Results}

\section{Gene flow in structured refuge system}

The purple-seeded corn provided a convenient means to track gene flow between refuge and neighbor plants, as shown in Fig. 1. The frequency of cross-pollination from the structured PS refuge plants varied widely among the four site-years, ranging from an overall average of 0.5 (LA-2014 site) to $5.9 \%$ (MD-2014 site) pooled over all ears sampled from rows adjacent to the structured refuge (Fig. 2). Percentages of purple kernels by row ranged from a high of $13.7 \%$ (first row, MD-2014) to $0.1 \%$ (fourth row, LA-2014).

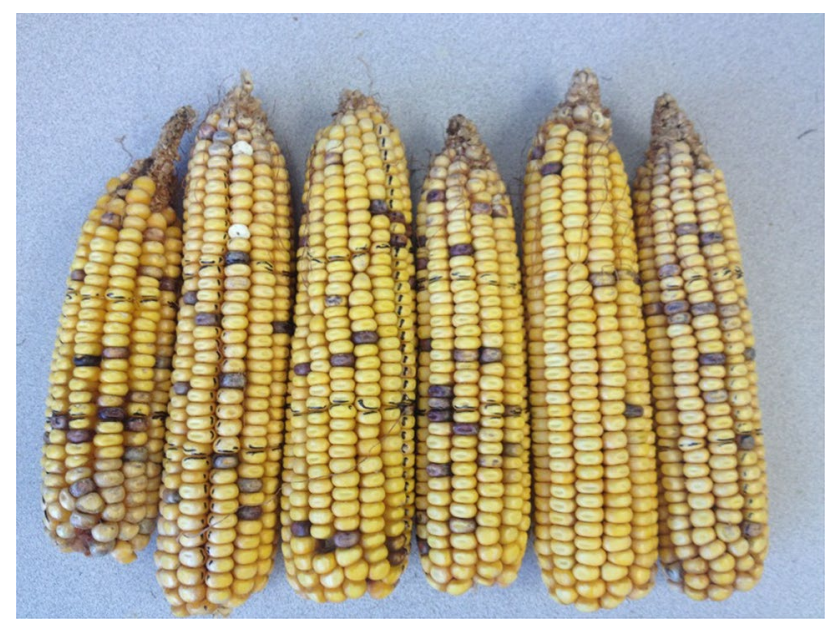

Fig. 1 Illustration of the phenotypic expression of the dominant purple-seeded trait resulting from cross-pollinated kernels in a seed blend system
With the exception of the LA-2013 site, the number of purple kernels declined significantly across rows moving away from the refuge plants (MD-2013: $F_{(3,32)}=40.1, P<0.001$; MD-2014: $F_{(3,16)}=20.3, P<0.001 ;$ LA-2013: $F_{(3,24)}=17.4$, $P<0.001)$. Overall numbers of purple kernels in the second, third, and fourth rows averaged $43.5,66.0$, and $75.2 \%$ less, respectively, compared to levels in the first row. Declining patterns of cross-pollination across rows were similar on each side of the refuge, as evident by nonsignificant interaction effects. However, the direction and amount of gene flow from the refuge plants was apparently affected by the prevailing winds, as evident by significantly higher percentages of purple kernels on the north side of the refuge block at MD-2014 site $\left(F_{(1,16)}=253.1, P<0.001\right)$.

\section{Gene flow in seed blend refuge system}

Seed blend system 2 was designed to measure the extent and distribution pattern of cross-pollination due to gene flow from a single PS refuge plant to neighboring plants. Figure 3 shows the mean percentage of purple kernels observed from two neighboring plants on both sides of the refuge plant within the row (P1-2), next three closest plants within the row (P3-5), and the closest consecutive plants on the immediate adjacent rows. The overall extent of gene flow of the purple trait from the refuge plant was substantially lower than levels observed in the structural refuge system, with purple kernels averaging $<1 \%$ on neighboring plants at all site-years. Consistent with the structural refuge results, the number of purple kernels was highest at the MD-2014 site, indicating that pollen movement among plants was apparently affected by wind conditions throughout all treatment plots. Outcrossing of the purple trait was generally higher in ears of within-row plants nearest to the refuge plant (P1-2), and also higher for plants in adjacent rows directly across from the refuge plant at the 2014 sites. However, plant position differences were not consistent and only significant for the MD-2013 data $\left(F_{(2,12)}=8.93, P=0.004\right)$.

For seed blend system 3 , the gene flow resulting from outcrossing of pollen from neighboring Bt PS plants to refuge plants was considerably higher, compared to gene flow in the opposite direction. The percentage of kernels expressing the purple trait in the refuge plants ranged from 4.8 to $30.9 \%$, with a mean of $18.6 \%( \pm 1.5)$.

\section{Feeding bioassay}

Bioassays of kernel tissue from refuge plants in 95:5\% seed blend plots showed clear evidence of Bt toxin expression. Each assay measured the body weight gain of individual second instars of $H$. zea and $O$. nubilalis that initially weighed an average of $0.32 \pm 0.053$ and $0.44 \pm 0.078$, respectively. For $H$. zea, significant weight differences were observed 


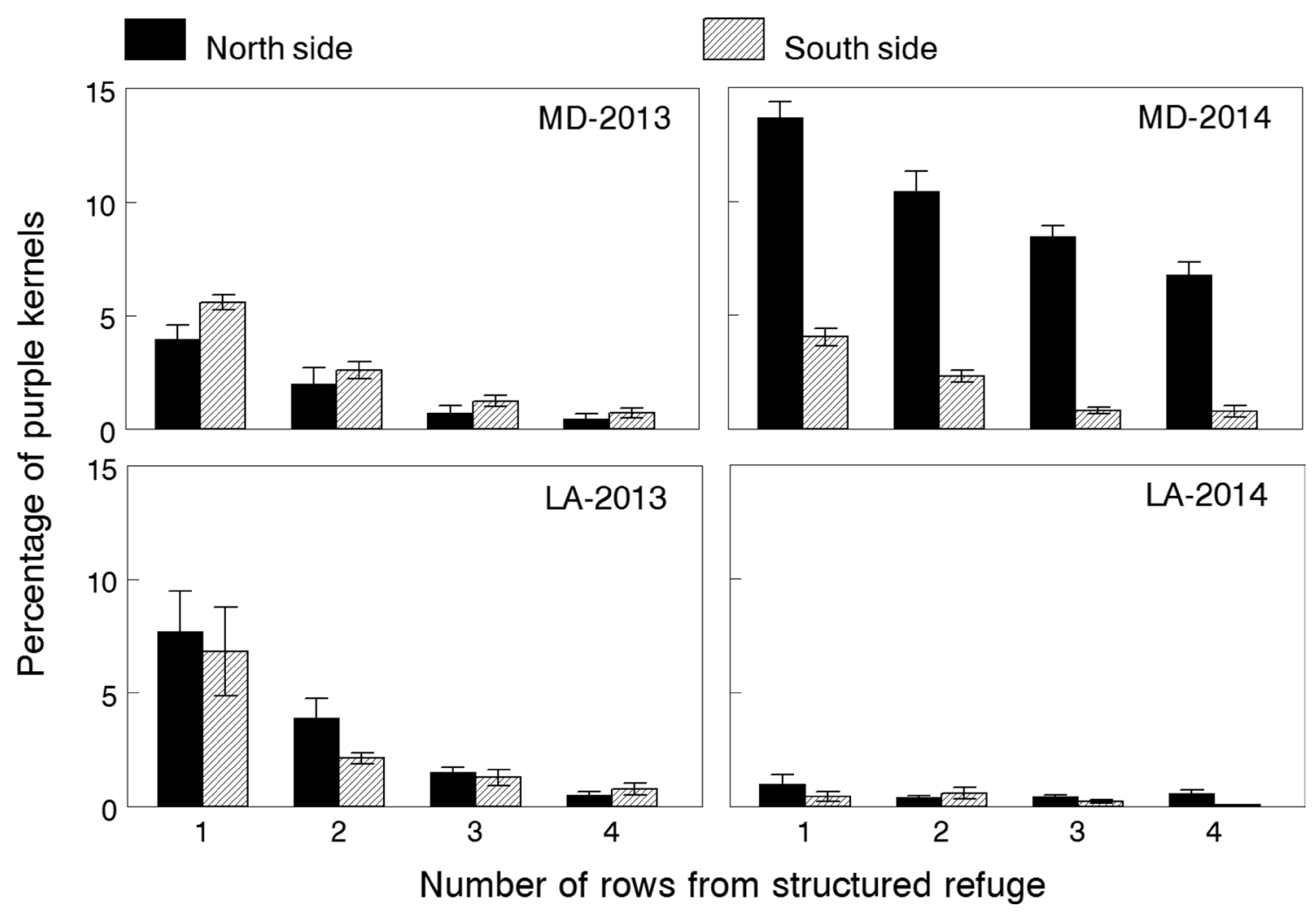

Fig. 2 Mean percentage $( \pm$ SEM) of purple kernels in ears of yellow-seeded corn plants in the structured refuge system involving a 4-row pure stand of non-Bt purple-seeded plants flanked on both sides by 4 rows of Bt yellow-seeded plants

when fed for 7 days on diet incorporated with the different types of kernel powder $\left(F_{(2,7)}=239.2, P<0.001\right)$ (Fig. 4). Weighs of larvae exposed to refuge kernel $(34.1 \pm 0.88 \mathrm{mg})$ and Bt kernel $(12.9 \pm 1.05 \mathrm{mg})$ powders were reduced by 37.7 and $76.5 \%$, in comparison with average weights $(54.8 \pm 1.42 \mathrm{mg})$ of larvae exposed to non-Bt kernel powder. For $O$. nubilalis larvae, growth inhibition was significantly greater when fed on diet incorporated with refuge kernel $\left(F_{(2,9)}=422.4, P<0.001\right)$ (Fig. 4). Weight gain of larvae exposed to refuge and Bt kernel powder were $97.1 \%$ and $99.0 \%$ inhibited, respectively, compared the mean weight of larvae $(41.3 \pm 1.97 \mathrm{mg})$ fed on non-Bt kernel tissue.

\section{Discussion}

In this study, we quantified gene flow in structured and seed blend refuge planting systems using a purple-seeded corn expressed as a single-gene, dominant trait. There were variable shades of the purple color because the phenotypic expression on kernels is probably influenced by epistasis and modification by other genes. However, assuming that $\mathrm{Bt}$ toxin expression is a dominant trait, this marker provided an effective way to measure the potential outcrossing of $\mathrm{Bt}$ genes to neighboring plants. At all sites, gene flow of the purple-seeded trait was observed in ears from the structured and seed blend refuge planting systems, but overall levels of outcrossing varied widely among the four site-years, as evident by the lowest levels observed at LA-2014 compared to the highest levels at MD-2014. Pollen movement and likelihood of cross-pollination among corn plants are influenced by environmental factors, such as temperature, prevailing winds, and wind speed (Jemison and Vayda 2001; Klein et al. 2003; Brookes et al. 2004; Purseglove 1972; Luna et al. 2001), which could have differed among sites. Although both hybrid types were planted at the same time at each site and had similar maturation times, pollen shed asynchronicity could account for some of the site differences. (Brookes et al. 2004).

In the structured refuge system, cross-pollination of ears on the first row next to the PS refuge plants resulted in an average of 5.4\% purple kernels, but decreased significantly across the remaining rows. Several studies have found relatively high levels of cross-pollinated kernels in the first row ( $0.8 \mathrm{~m}$ from $\mathrm{Bt}$ corn) of non-Bt corn planted adjacent to $\mathrm{Bt}$ corn, with levels ranging from 3 to $82 \%$ (Byrne and Fromherz 2003; Ma et al. 2004; Bannert et al. 2008). Lowest levels of cross-pollination (1.3\% overall mean) were observed in the fourth row, a 75\% drop at $2.5 \mathrm{~m}$ from the nearest purple-seeded plants. Corn pollen is one of the heaviest of 


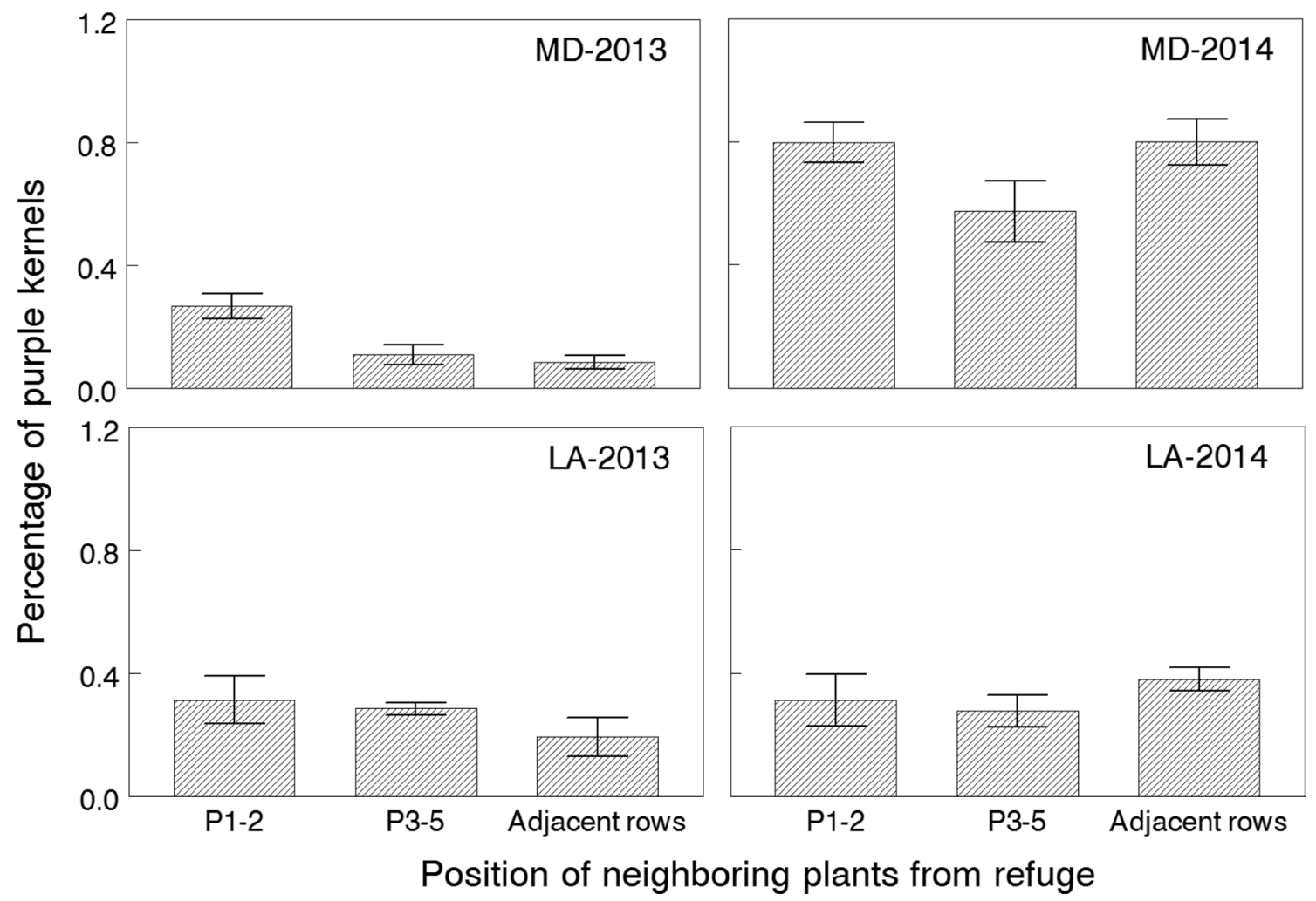

Fig. 3 Mean percentage ( \pm SEM) of purple kernels in ears of yellowseeded corn plants nearest to purple-seeded refuge plants in a seed blend system. Data are given for the two neighboring plants on both

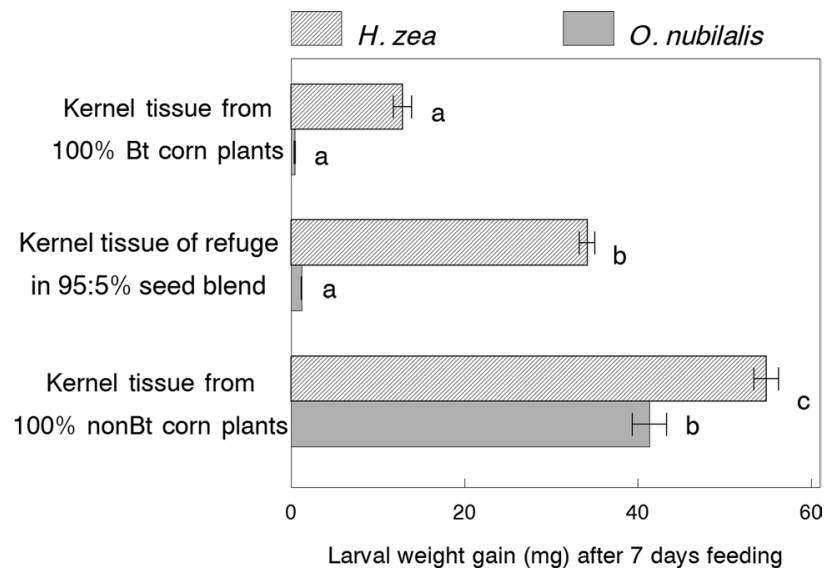

Fig. 4 Mean larval weight gain $( \pm \mathrm{SEM})$ of $H$. zea and $O$. nubilalis second instars after feeding for 7 days on a meridic diet containing $6 \%$ corn kernel tissue from (1) pyramided Bt11 $\times$ MIR162 ears, (2) isoline non-Bt ears, and (3) refuge ears from a seed blend planting of $95 \%$ pyramided Bt $11 \times$ MIR162. Mean bars for each insect species with the same letter are not significantly different $(P<0.05)$

the wind-pollinated plants (Brookes et al. 2004), and studies reported off-field pollen deposition dropped by $50-75 \%$ over distances of 2-4 $\mathrm{m}$ from the field edge (Pleasants et al. sides of the refuge plant within the same row (P1-2), next three closest plants within the row (P3-6), and the closest two consecutive plants on the immediate adjacent rows

2001), and cross-pollination inside the field declined by one-half over a distance of $3.8 \mathrm{~m}$ (Bateman 1947). Relative changes in cross-pollination across rows were similar on each side of the structured refuge, but the overall extent of gene flow was significantly different, particularly at the MD-2014 site, and likely influenced by direction and speed of the prevailing winds. The movement of corn pollen also depends on whether the wind is moving horizontally or vertically. Ma et al. (2004) found that the large variation in pollen dispersal is likely because of vertical wind moving pollen upward rather than horizontal wind movement of pollen. According to Chilcutt and Tabashnik (2004), gene flow from refuge to Bt plants or vice versa depends on many factors, including refuge size shape, distance from the $\mathrm{Bt}$ plants, wind speed and direction and similarity in maturation times between the $\mathrm{Bt}$ and non-Bt hybrids. It is noted that the extent and distribution of outcrossing measured by the structural refuge system represents gene flow in both directions; thus, the results provide a relative measurement of the 'halo effect' at a local field level, where at the interface of the $\mathrm{Bt}$ and non-Bt plantings, increased larval mortality may occur because non-Bt ears are pollinated by Bt pollen (Alstad and Andow 1995; Burkness et al. 2011). 
In the seed blend refuge plantings, gene flow of the purple-seeded trait was measured in both directions, resulting in very different levels of cross-pollination. Outcrossing of pollen from the refuge plant averaged less than $1 \%$ in ears of neighboring Bt plants both within and on adjacent rows at all site-years. Cross-pollination of the purple trait was generally higher for plants nearest to the refuge plant, but differences were not consistent. On the assumption that expression of purple seeds demonstrates the actual movement of non-Bt genes to neighboring Bt plants, this route of outcrossing should have negligible effects on the overall expression of $\mathrm{Bt}$ toxins in kernels of Bt plants. The results suggest that the very low levels of gene outcrossing from refuge plants to Bt plants in a 95:5\% seed blend will not have major consequences for IRM or insect damage. Burkness et al. (2011) also showed no change in survival of $H$. zea on Bt plants pollinated with non-Bt pollen. However, given the close spatial relationship of tassels and ears of individual plants in a 95:5\% seed blend and the huge amounts of pollen dispersed (2-5 million grains per plant) within the corn canopy (Goss 1968), the potential for outcrossing from Bt to refuge plants was understandably much greater, averaging $18.6 \%$ or about 24X higher than the gene flow from the refuge plants. Studies report that more than $95 \%$ of the kernels of an individual plant may be fertilized by pollen from neighboring plants (Emberlin et al. 1999; Poehlman and Sleper 1995). Under these conditions, it is surprising that only $18.6 \%$ of the refuge ear kernels expressed the dominant purple trait. As mentioned above, asynchronous pollen shed and silking may have limited the opportunity for the neighboring purple-seeded plants to fertilize the refuge ears. Nevertheless, this route of gene contamination could confer a selective advantage to Bt-resistant heterozygotes over homozygous susceptible larvae in the refuge plants.

The results of the diet-incorporated kernel tissue bioassay provide direct evidence, indicating that a relatively high percentage of the kernels in a refuge ear in a seed blend system can express Bt toxins. Consumption of kernel tissue collected at full physiological maturity from refuge plants in a 95:5\% seed blend caused significant growth inhibition of both $H$. zea and $O$. nubilalis larvae $37.7 \%$ and $97.1 \%$ less weight gain, respectively, compared to larvae exposed to nonBt kernel powder). It is noteworthy that this amount of inhibition resulted from exposure to Bt toxins in kernel powder consisting of only $6 \%$ of the diet by weight. Similarly, Yang et al. (2014) reported that a 95:5\% seed blend planting of Bt corn containing the SmartStax traits expressing Cry1A.105, Cry2Ab2, and Cry1F did not provide an effective refuge for H. zea. Cross-pollination caused $>90 \%$ of the refuge kernels to express one or more Bt toxins, which reduced the neonateto-adult survivorship of $H$. zea to only $4.6 \%$, a reduction of $88.1 \%$ relative to larvae feeding on non-Bt corn ears. O. nubilalis is significantly more susceptible to the $\mathrm{Bt}$ toxins than
H. zea; thus, it is not surprising that larvae fed for 7 days on refuge kernels gained relatively little weight, which was not significantly different from virtually no weight gain of larvae exposed to the Bt kernel powder. However, simulation models by Kang et al. (2012) predicted that resistance evolution in $O$. nubilalis is not significantly expedited by Bt gene outcrossing in kernels of non-Bt corn because ears are available only for the second generation of $O$. nubilalis; and only a fraction of the second generation larvae invade the ears; and mortality caused by $\mathrm{Bt}$ toxins expressed in refuge ears is not high. In support of these model predictions, field plot experiments with the sugarcane borer, Diatraea saccharalis (F.), found that the number of larvae infesting non-Bt plants in a 95:5\% seed blend planting of $\mathrm{Bt}$ and non-Bt corn was not significantly reduced, compared to the pure stand of non-Bt corn (Wangila et al. 2013). These results suggest that refuge plants in the seed blend are able to provide a comparable refuge population of $D$. saccharalis compared to a structured refuge planting. We agree that $O$. nubilalis is less likely to be exposed to the selection pressure exerted on larvae feeding on a Bt-expressing kernels in refuge ears. However, a companion study using plots of the same siteyears reported that the seed blend did not produce as many susceptible individuals as those produced in a structured refuge, as a result of movement of larvae to neighbor Bt plants, where they were killed by the high dose trait (Oyediran et al. 2015).

Overall findings of this study show that cross-pollination of Bt plants with pollen from refuge plants has negligible effects on toxin expression in Bt ears, compared to the opposite route of outcrossing by Bt pollen in a seed blend. Our results agree with studies by Chilcutt and Tabashnik (2004) and Yang et al. (2014) that gene flow from Bt plants to refuge plants is high, resulting in a mosaic of kernels expressing intermediate doses of toxins that can reduce the number of homozygous susceptible larvae produced and favor survival of heterozygotes. Bioassay results showed significant growth inhibition of larvae fed kernel tissue from refuge plants, which is clear evidence that selection for resistance can occur on non-Bt plants in a seed blend. To preserve the durability of the Bt corn, now widely planted as seed blends, this study underscores the need for additional research to better understand the pattern of mosaic toxin expression in cross-pollinated refuge ears and its effects on the behavior and survival of both heterozygotes and susceptible homozygotes of ear-feeding pests, particularly $\mathrm{H}$. zea.

\section{Author contributions statement}

IO, TB, and SM conceived and designed the research. GD and FH conducted the experiments and analyzed the data. GD wrote the draft manuscript, and all authors read, revised, and approved the manuscript. 
Acknowledgements We express appreciation to the University of Maryland Agriculture Experiment Station and Louisiana State University Agricultural Center for providing research farm support for the project. We thank our Syngenta colleagues for help in study design and preparation of the manuscript. Mention of trade names or commercial products in this publication is solely for the purpose of providing specific information and does not imply recommendation or endorsement by University of Maryland and Louisiana State University Agricultural Center.

Funding Partial support was provided by a cooperative research agreement with Syngenta Crop Protection, along with internal support from the Maryland IPM Extension and Agriculture Experiment Station, and Louisiana State University Agricultural Center.

\section{Compliance with ethical standards}

Conflict of interest GD and FH have received research grants from Syngenta Crop Protection for other related studies. The authors declare that they have no conflict of interest.

Ethical approval This article does not contain any studies with human participants or animals performed by any of the authors.

Open Access This article is distributed under the terms of the Creative Commons Attribution 4.0 International License (http://creativeco mmons.org/licenses/by/4.0/), which permits unrestricted use, distribution, and reproduction in any medium, provided you give appropriate credit to the original author(s) and the source, provide a link to the Creative Commons license, and indicate if changes were made.

\section{References}

Alstad DN, Andow DA (1995) Managing the evolution of insect resistance to transgenic plants. Science 268:1894-1896

Aylor DE (2002) Settling speed of corn (Zea mays) pollen. J Aerosol Sci 33:1601-1607

Aylor D, Schultes N, Shields E (2003) An aerobiological framework for assessing cross-pollination in maize. Agric For Meteorol 119:111-129

Bannert M, Vogler A, Stamp P (2008) Short-distance cross-pollination of maize in a small-field landscape as monitored by grain color markers. Eur J Agron 29:29-32

Bateman AJ (1947) Contamination of seed crops II. Wind pollination. Heredity 1:235-246

Brookes G, Barfoot P, Mele E, Messeguer J, Benetrix F et al (2004) Genetically modified maize: pollen movement and crop coexistence. PG Economics Ltd., Dorchester

Burkness EC, Hutchison WD (2012) Bt pollen dispersal and Bt kernel mosaics: integrity of non-Bt refugia for lepidopteran resistance management in maize. J Econ Entomol 105:1773-1780

Burkness EC, O'Rourke PK, Hutchison WD (2011) Cross-pollination of nontransgenic corn ears with transgenic Bt corn: efficacy against lepidopteran pests and implications for resistance management. J Econ Entomol 104:1476-1479

Byrne PF, Fromherz S (2003) Can GM and non-GM crops coexist? Setting a precedent in Boulder County, Colorado, USA. J Food Agric Environ 1:258-261

Chilcutt CF, Tabashnik BE (2004) Contamination of refuges by Bacillus thuringiensis toxin genes from transgenic maize. Proc Natl Acad Sci USA 101:7526-7529
Chilcutt CF, Tabashnik BE (2014) Gene flow from transgenic Bt corn to non Bt corn refuges. http://www.isb.vt.edu/articles/jul04 01.htm. Retrieved 21 Nov 2018

Emberlin J, Adams-Groom B, Tidmarsh J (1999) A report on the dispersal of maize pollen. National Pollen Research Unit, University College, Worcester. http://www.soilassociation.org

Goss JA (1968) Development, physiology, and biochemistry of corn and wheat pollen. Botanic Rev 34:333-358

Gould F (1998) Sustainability of transgenic insecticidal cultivars: integrating pest genetics and ecology. Annu Rev Entomol 43:701-726

Heuberger S, Ellers-Kirk C, Yafuso C, Gassmann AJ, Tabashnik BE et al (2008) Effects of refuge contamination by transgenes on $\mathrm{Bt}$ resistance in pink bollworm (Lepidoptera: Gelechiidae). J Econ Entomol 101:504-514

Horner TA, Dively GP, Herbert DA (2003) Development, survival and fitness performance of Helicoverpa zea (Lepidoptera: Noctuidae) in MON-810 Bt field d corn. J Econ Entomol 96:914-924

Huang F, Andow DA, Buschman LL (2011) Success of the high dose/ refuge resistance management strategy after 15 years of Bt crop use in North America. Entom Exp Appl 140:1-16

Jemison JM, Vayda ME (2001) Cross pollination from genetically engineered corn: wind transportation and seed source. AgBioForum 4:87-92

Kang J, Onstad DW, Hellmick RL, Moser SE, Hutchison WD, Prasifka JR (2012) Modeling the impact of cross-pollination and low toxin expression in corn kernels on adaptation of European corn borer (Lepidoptera: Crambidae) to transgenic insecticidal corn. Environ Entomol 41:200-211

Klein EK, Lavigne C, Foueillassar X, Gouyon PH, Laredo C (2003) Corn pollen dispersal: quasi-mechanistic models and field experiments. Ecol Monographs 73:131-150

Kuparinen A, Schurr F, Tackenberg O, O'Hara RB (2007) Air-mediated pollen flow from genetically modified to conventional crops. Ecol Appl 17:431-440

Luna VS, Figueroa MJ, Baltazar L, Gomez R, Townsend R, Schoper JB (2001) Maize pollen longevity and distance isolation requirements for effective pollen control. Crop Sci 41:1551-1557

Ma BL, Subedi KD, Reid LM (2004) Extent of cross-fertilization in maize by pollen from neighboring transgenic hybrids. Crop Sci 44:1273-1282

Matten SR, Frederick RJ, Reynolds AH (2012) United States Environmental Protection Agency insect resistance management programs for plant-incorporated protectants and use of simulation modeling. In: Wozniak CA, McHughen A (eds) Regulation of agricultural biotechnology: the United States and Canada. Springer, Berlin, pp 175-267

Onstad DW, Mitchell PD, Hurley TM, Lundgren JG, Porter RP, Krupke CH, Spencer JL, DiFonzo CD, Baute TS, Hellmich RL et al (2011) Seeds of change: corn seed mixtures for resistance management and integrated pest management. J Econ Entomol 104:343-352

Oyediran I, Dively GP, Huang F, Burd T (2015) Evaluation of European corn borer Ostrinia nubilalis (Lepidoptera: Crambidae) larval movement and survival in structured and seed blend refuge plantings. Crop Prot 81:145-153

Pleasants JM, Hellmich RL, Dively GP, Sears MK, Stanley-Horn DE, Mattila HR et al (2001) Corn pollen deposition on milkweeds in and near cornfields. Proc Natl Acad Sci USA 98:11919-11924

Poehlman JM, Sleper DA (1995) Breeding field crops. Iowa State University Press, Ames

Purseglove JW (1972) Tropical crops. Chapter 1: Monocotyledons. Longman Group, London

SAS Institute (2013) SAS/STAT user's, 3rd edn. SAS Institute Inc, Cary 
Tabashnik BE, Gassmann AJ, Crowder DW, Carrière Y (2008) Insect resistance to Bt crops: evidence versus theory. Nat Biotechnol 26:199-202

USEPA-FIFRA (2011) Insect resistance management for SmartStax Refuge-in-the-Bag, a plant-incorporated protectant (PIP) corn seed blend. In: SAP Minutes No. 2011-02. FIFRA Scientific Advisory Panel Meeting, 8-9 December 2010 Arlington

Wangila DS, Leonard BR, Ghimire MN, Bai Y, Zhang L, Yang Y et al (2013) Occurrence and larval movement of Diatraea saccharalis (Lepidoptera: Crambidae) in seed mixes of non-Bt and Bt pyramid corn. Pest Manag Sci 69:1163-1172

Yang F, Kerns DL, Head GP, Leonard BR, Levy R, Niu Y, Huang F (2014) A challenge for the seed mixture refuge strategy in $\mathrm{Bt}$ maize: impact of cross-pollination on an ear-feeding pest, corn earworm. PLoS ONE 9(11):e112962. https://doi.org/10.1371/ journal.pone.0112962

Yang F, Kerns DL, Brown S, Huang F (2017) Pollen contamination in seed mixture increases the dominance of resistance to Bt maize in Spodoptera frugiperda (Lepidoptera: Noctuidae). Pest Manag Sci 73:2379-2385. https://doi.org/10.1002/ps.4631

Publisher's Note Springer Nature remains neutral with regard to jurisdictional claims in published maps and institutional affiliations. 